\title{
The use of Rose Angina Questionnaire and 12 lead Electrocardiogram (ECG) in the Identification of potential Ischemic Heart Changes among a group of Hypertensive Patients in Sri Lanka
}

\author{
BMC. Rathnayake ${ }^{1 *}$, R. P. Illeperuma², U. Ralapanawa ${ }^{3}$, T.A. Jayalath ${ }^{3}$
}

\begin{abstract}
Introduction: Ischemic heart diseases (IHDs)are a leading cause of mortalities in Sri Lanka. Among a variety of risk factors, hypertension is a leading cause for IHDs; however, unequal distribution of proper diagnostic facilities complicates the early diagnosis of ischemic changes among adults in Sri Lanka. Therefore this study aimed at studying the possibility of using two basic diagnostic tools, including Rose angina questionnaire (RAQ) and 12 lead electrocardiogram ( $E G C)$, to estimate the potential ischemic heart changes among the hypertensive patients in a selected Sri Lankan adult population.

Methods: A consecutive sample of 150 hypertensive individuals was recruited, and data were gathered through an interviewer-administered questionnaire, RAQ, blood pressure measurement, and ST-segment analysis of standard 12 -lead ECG recordings.

Results and Discussion: The majority of the participants $(n=93,62 \%)$ were females. The mean age was $61.5 \pm 10.33$ years, and their average systolic and diastolic blood pressures were $146 \pm 23.27 \mathrm{Hgmm}$ and $85 \pm 12.08 \mathrm{Hgmm}$. The association of ST-segment deviations that denote IHDs and the presence of stage I or II hypertension $(n=52,42 \%)$ was statistically significant $(p<0.05, d f=1)$. Based on positive responses to both RAQ and ST-segment deviations, the proportion of individuals with potential Ischemic Heart changes among the hypertensive individuals was $23 \%$ (34/150). Except these, 37/150 (25\%) of hypertensive individuals, exhibited potential ischemic heart changes only in 12 lead ECG, but the responses to RAQ were negative. On the other hand, responses RAQ was positive among 32/150 (21\%) individuals, though none of them exhibited any significant ST-segment changes in their 12 lead ECGs.

Conclusion: Based on the utility of RAQ and 12 lead ECG, about a quarter of hypertensive individuals could be detected as having potential ischemic heart changes. Therefore it is suggested that RAQ can be incorporated along with 12 lead ECG into the routine clinical assessment to identify the risk of IHDs among Sri Lankan hypertensive individuals.
\end{abstract}

Keywords: Ischemic Heart Diseases, Rose Angina Questionnaire, ST analysis, 12 lead ECG, Hypertension,

Asian Pac. J. Health Sci., (2020); DOI: 10.21276/apjhs.2020.7.2.3

\section{INTRODUCTION AND BACKGROUND}

Ischemic heart diseases (IHDs) is one of the prominent categories of cardio vascular diseases (CVDs) in which the myocardium is affected by diminished blood supply causing myocardial injury and unless the condition is diagnosed promptly it can lead to cardiac arrest or sudden death even. According to the statistics of "Annual Health Bulletin-2014" published by the health ministry of Sri Lanka, IHDs caused 30.6 deaths per 100,000 populations. Thus IHDs holds the $1^{\text {st }}$ rank among the leading causes of hospital deaths in Sri Lanka. ${ }^{[1]}$

The IHDs are caused by a variety of risk factors while hypertension is one of the leading modifiable risk factors. ${ }^{[2,3]}$ As detected by ischemic changes in the ECGs, Katulanda P et al. in 2010 has highlighted that the prevalence of IHDs in Sri Lanka is $7.2 \%{ }^{[4]}$ Importantly, one-third of the Sri Lankan adult population is hypertensive but unfortunately a considerable proportion of individuals living with hypertension are still not diagnosed and hypertension is highly prevalent among urban adults as compared to rural adults in Sri Lanka. ${ }^{[5]}$

In detecting ischemic changes of the myocardium, the morphology of ST-segment in 12 lead ECG can be analyzed, which represents the phase between ventricular depolarization and ventricular repolarization. In the case of myocardial ischemia, the normal wave pattern of the ST segment can either be altered into downwards (ST depression) in the ECG leads facing to the anatomically opposite to the ischemic myocardium or upwards (ST elevation) in the leads facing to the ischemic zone. ${ }^{[6]}$ Since the earliest manifestations of myocardial ischemia are typically ST-segment and T wave changes, the $3^{\text {rd }}$ universal definition
'Department of Nursing, Faculty of Allied Health Sciences, University of Peradeniya, Sri Lanka.

${ }^{2}$ Department of Medical Laboratory Sciences, Faculty of Allied Health Sciences, University of Peradeniya, Sri Lanka.

${ }^{3}$ Department of Medicine, Faculty of Medicine, University of Peradeniya, Sri Lanka.

Corresponding Author: BMC. Rathnayake, Department of Nursing, Faculty of Allied Health Sciences, University of Peradeniya, Sri Lanka, Email: chameesh@gmail.com

How to cite this article: Rathnayake BMC, Illeperuma RP, Ralapanawa $\mathrm{U}$, Jayalath TA. The use of Rose Angina Questionnaire and 12 lead ECG in the identification of potential Ischemic Heart Changes among a group of hypertensive patients in Sri Lanka. Asian Pac. J. Health Sci,, 2020; 7(2):12-17

Source of support: The university research grant (URG/2016/98/AHS) of the University of Peradeniya, Sri Lanka

Conflict of interest: None

Received: 25/02/2020 Revised: 28/03/2020 Accepted: 01/04/2020

on myocardial infarction has introduced a modified criterion to determine the ST-segment deviations in different leads which is useful in the detection of ischemic changes (Table 1).

Chronic hypertension is associated with ECG abnormalities such as ST depressions and T wave inversion. ${ }^{[7]}$ It was identified that among 100 hypertensive patients studied, 23 experienced 72 episodes of ST-segment depression. During these ST depressions, systolic BP increased by $9+/-15 \mathrm{Hg} / \mathrm{mm}$, Diastolic BP 7+/- $11 \mathrm{Hgmm}$ thus it was concluded that BP elevations trigger the episodes of 
Table 1: Modified criteria to detect ischemia based on ST-segment deviation ( $3^{\text {rd }}$ universal definition of myocardial infarction)

\begin{tabular}{ll}
\hline ST-elevation & New ST elevation at the J point in two contiguous leads with the cut-points: $\geq 0.1 \mathrm{mV}$ in all leads other \\
& than leads $\mathrm{V} 2-\mathrm{V} 3$ where the following cut-points apply: \\
& $\geq 0.2 \mathrm{mV}$ in men $\geq 40$ years \\
& $\geq 0.25 \mathrm{mV}$ in men $<40$ years \\
& $\geq 0.15 \mathrm{mV}$ in women \\
ST depression and T wave changes & New horizontal or down-sloping ST depression $\geq 0.05 \mathrm{mV}$ in two contiguous leads and/or T inversion $\geq$ \\
& $0.1 \mathrm{mV}$ in two contiguous leads with prominent $\mathrm{R}$ wave or $\mathrm{R} / \mathrm{S}$ ratio $>1$.
\end{tabular}

ST-segment depression, that denotes the ischemic changes in the heart. ${ }^{[3]}$

A study conducted in Italy in 1998 to assess the prevalence of ST-segment depressions in a sample of patients with essential hypertension has revealed that $15 \%$ of patients out of 411 , experienced ST-segment depressions during Holter ECG monitoring and exercise ECG test. ${ }^{[8]}$ Uen S et al. in 2003 conducted a study recruiting 63 patients with both hypertension and IHDs, to identify the determinants of ST-segment depression, by monitoring 24 hour ECG and blood pressure using an ambulatory device. Importantly, all the ST-segment depressions were silent, which occurred during the increase of systolic blood pressure by $15+/-11 \mathrm{Hgmm}$ and diastolic blood pressure by $10+/-5 \mathrm{Hgmm}^{[9]}$

Meanwhile, RAQ developed by G. A. Rose in 1962, is a commonly used tool in overseas health settings to detect such ischemic chest pain. Based on the various research studies in which the RAQ was used, it has a high average specificity (80\%-95\%) and a variable sensitivity $(19 \%-83 \%)$ in predicting ischemic cardiovascular conditions. ${ }^{[10]}$ The original RAQ consists of seven questions, and even a single positive response to a particular question indicates the possibility of myocardial infarction. ${ }^{[11]}$ The validity of RAQ results against the exercise electrocardiography for screening IHDs includes $80 \%$ of sensitivity and $31.1 \%$ specificity. Hence, the use of $R A Q$, along with resting ECG is a cost-effective method for screening the risk of coronary heart diseases. ${ }^{[12]}$

The evidence of ECG findings of the study of Mendis. S and Ekanayaka. E. M in 1994, which was carried out among the middleaged men in Central Sri Lanka, suggests that ECG changes in the study population were associated with many underlying risk factors. In this study, the definitive evidence of IHDs (positive symptoms and ECG changes of ischemia) was $16 / 1000$ (95\% CL, 9-27) followed by the evidence on ECG changes of ischemia without symptoms was 32/1000 (95\% CL, 21-46). ${ }^{[13]}$

As hypertension has been recognized as a prominent but modifiable risk factor for IHDs nevertheless due to the lack of advanced diagnostic methods in the most of local health care settings, the hypertensive patients who are still asymptomatic but at risk of IHDs probably miss the opportunity to undergo early screening and detection of potentially preventable myocardial ischemic changes. Further, they lack the opportunity to undergo detailed early screening methods like RAQ due to the rush in overcrowded clinics conducted at the hospitals in Sri Lanka. Therefore interviewing such patients who suffer from underlying different medical conditions using the RAQ along with an ECG measurement will be more effective in identifying the possibility of IHD early.

Even though several studies have been conducted in Sri Lanka with the administration of RAQ, most of these studies have incorporated only a defined group of patients such as diabetic patients, ${ }^{[14]}$ and patients who suffered from chest pain. ${ }^{[15]}$ As the early detection of ischemic changes of the myocardium is important in further clinical management, it is very productive to integrate advanced technology in screening the individuals who are at risk of developing an IHD. As discussed above, identifying the changes in the morphology of ST-segment of standard 12 lead ECG in vulnerable individuals may lead to the initiation of appropriate clinical management at an early stage saving their lives.

Despite the few numbers of studies that have been carried out regarding the IHDs and its diagnosis in Sri Lanka, there is a lack of recently published research findings related to the study of IHDs in central Sri Lanka.

Therefore the current study aimed at studying the effectiveness of utilizing RAQ and considering morphological patterns of ST-segment of standard 12 lead EGC with reference to the $3^{\text {rd }}$ Universal definition of Myocardial Infarction to estimate the potential ischemic heart changes routinely, among the hypertensive patients in a selected Sri Lankan adult population.

\section{Study Methodology}

\section{Research Design}

A descriptive cross-sectional study was carried out recruiting diagnosed hypertensive patients who are registered and attend to the hypertension clinic of Teaching Hospital, Peradeniya, Sri Lanka. Approximately there are about 800 patients who participate at this hypertension clinic, monthly. The data collection comprised of two sessions of data collection including,

- Date collection using an interviewer-administered questionnaire and RAQ.

- Connection of each patient to a portable bedside cardiac monitor to obtain a standard 12 -lead ECG, ST-segment analysis report and vital signs (pulse rate, systolic blood pressure, diastolic blood pressure, mean arterial pressure)

The data were gathered once in every two weeks from December 2018 to May 2019. According to the sample size estimation, the required number of patients to be studied was 150 . Thus consecutive 150 diagnosed hypertensive patients attending the hypertension clinic were interviewed during the study period. About 12 patients were selected conveniently to be interviewed per day and a reference code was mentioned in their clinic record in order to avoid repetition of recruiting the same patient on a subsequent clinic day.

\section{Data Collection Method}

For the first part of data collection, an interviewer-administered questionnaire, along with a standard version of RAQ was used. Before the data collection, this questionnaire was validated by administering it to 10 hypertensive individuals who were not recruited to the study and their comments and responses were considered for the modification of the questionnaire. The Components of the interviewer-administered questionnaire mainly included demographic data, Family history of non-communicable diseases (e.g., diabetes mellitus (DM), hypertension, IHDs, hypercholesterolemia, cancer, etc.) and details of the underlying disease (e.g., DM, hypertension, hypercholesterolemia, hepatic 
impairment, etc.). The presence of concurrent disease conditions was emphasized by cross-checking with the clinic records and medication cards. In the second part of data collection, the patient was attached to the portable bedside patient monitor (MindrayiMEC 15), and two standard 12 lead ECG strips, ST analysis reports, ECG rhythm strip, and vital signs were recorded. One ECG recording was given to the patient and feedback regarding the ECG recording was also provided. All the interviews were led by the principal investigator, and the assistance from a female technical officer was seeking when the ECGs were recorded from female patients. The ECG recording was followed by two automated blood pressure measurements in 10 minutes apart while the patient was on supine position, using the same MindrayiMEC 15 cardiac monitor.

\section{Ethical Clearance and Permission}

The ethical clearance for the study was obtained from the Ethics Review Committee of Faculty of Allied Health Sciences, University of Peradeniya, Sri Lanka (AHS/ERC/2017/006). Permission for conducting the study was obtained from the Director and In-charge Consultant Physician of Hypertension Clinic, Teaching Hospital, Peradeniya, Sri Lanka. The purpose of the study was well explained to the participants in their native language, and informed consent was sought from them prior to the data collection.

\section{Data analysis}

In a particular ECG of a patient, the direction of ST-segment was analyzed based on the ST segment analysis report recorded by the Mindrayimec 15 cardiac monitor, which indicated the ST segment measurement in $\mathrm{mV}$ in each lead. The height $(\mathrm{mm})$ and the deviation of the $T$ wave in each lead were also measured in each ECG recording by the principal investigator to eliminate the interobserver variability, and the identification of significant ST-segment changes was based on the $3^{\text {rd }}$ Universal Definition of Myocardial Infarction (Table 1). The frequencies, percentages, chisquare test, and odds ratios were used to determine the possible association between different risk categories.

\section{Results of the Study}

The age of the study population distributed from 29-80 years with the mean age of $61.5 \pm 10.33$ years. The majority of the study participants were females $(n=93,62 \%)$, while the rest is male ( $n$ $=57,28 \%$ ) hypertensive patients. The gender-wise frequencies of demographic data along with average systolic (SBP), diastolic (DBP), and mean arterial (MAP) blood pressures are indicated in Table 2.

A considerable number of study patients were diagnosed with stage II hypertension $(n=86,57 \%)$, and importantly a considerable proportion also had a MAP more than $100 \mathrm{Hgmm}(n=84,56 \%)$, respectively (Table 3 ). The frequencies of different blood pressure (BP) categories along with the average systolic (SBP) and diastolic (DBP) blood pressures are indicated in the Table 3.

Importantly, the clinic records and the medication cards indicated that about $70 \%(n=105)$ of the study population had concurrent Non Communicable Disease (NCD) conditions other than hypertension and among them, hypercholesterolemia $(n=67,44 \%)$ was most frequent followed by DM ( $n=10,7 \%)$ (Figure 1).

Table 2: The frequencies of demographic data along with average systolic (SBP), diastolic (DBP), and mean arterial (MAP) blood pressures in Hgmm.

\begin{tabular}{|c|c|c|c|c|c|}
\hline Demographic Factor & Category & Frequency (\%) & $S B P( \pm S D)$ & $D B P( \pm S D)$ & $M A P( \pm S D)$ \\
\hline \multirow[t]{2}{*}{ Gender } & Male & $57(38)$ & $135.88(24.36)$ & $81.75(10.36)$ & $98.54(10.36)$ \\
\hline & Female & $93(62)$ & $152.54(17.07)$ & $87.15(12.64)$ & $107.3(15.38)$ \\
\hline \multirow[t]{3}{*}{ Age } & 40 years or less & $3(2)$ & $136.33(11.84)$ & $89.67(10.5)$ & $92.33(22.5)$ \\
\hline & $41-60$ years & $59(39)$ & $146.78(22.55)$ & $89.56(10.9)$ & $106.6(15.07)$ \\
\hline & $61-80$ years & $88(59)$ & $146.16(24.12)$ & 81.95 (11.98) & $102.6(13.27)$ \\
\hline \multirow[t]{2}{*}{ Employment } & Employed & $76(51)$ & $139.36(27.21)$ & 82.09 (9.73) & 99.88 (10.06) \\
\hline & Not employed & $74(49)$ & $153.24(16.10)$ & $88.19(13.47)$ & $108.18(16.68)$ \\
\hline \multirow[t]{4}{*}{ Education level } & Primary education & $34(23)$ & $149.82(20.78)$ & $86.88(10.37)$ & $106.21(12.69)$ \\
\hline & Upto O/L & $78(52)$ & $144.82(22.72)$ & $85.31(12.15)$ & $102.99(14.18)$ \\
\hline & Upto A/L & $35(23)$ & $147.03(26.31)$ & $83.46(13.60)$ & $104.57(16.41)$ \\
\hline & Graduate & $3(2)$ & 126.5 (19.09) & $74(8.48)$ & $93(4.24)$ \\
\hline \multicolumn{2}{|c|}{ Total number of patients } & 150 & & & \\
\hline
\end{tabular}

Table 3: The frequencies of different blood pressure parameters along with average systolic (SBP) and diastolic (DBP) blood pressures in Hgmm.

\begin{tabular}{lllll}
\hline & Category & Frequency $(\%)$ & $S B P( \pm S D)$ & $D B P( \pm S D)$ \\
\hline Blood Pressure & & & & \\
Normal BP & SBP $<120$ and DBP $<80$ & $16(11)$ & $114.88(3.98)$ & $72.56(5.51)$ \\
Elevated BP & SBP 120-129 and DBP <80 & $13(9)$ & $127.38(3.15)$ & $75.23(6.24)$ \\
Stage I hypertension & SBP 130-139 or DBP 80-89 & $35(23)$ & $134.4(4.72)$ & $82.11(5.85)$ \\
Stage II hypertension & SBP $>140$ or DBP $>90$ & $86(57)$ & $159.69(21.36)$ & $90.14(12.55)$ \\
Mean arterial pressure & Less than $100 \mathrm{Hg} / \mathrm{mm}$ & $66(44)$ & $131.24(12.41)$ & $76.98(7.85)$ \\
& More than $100 \mathrm{Hg} / \mathrm{mm}$ & $84(56)$ & $157.96(23.10)$ & $91.48(10.96)$ \\
Duration of hypertension & 10 or less than years & $108(72)$ & $144.46(21.10)$ & $84.66(11.26)$ \\
& More than 11 years & $42(28)$ & $150.69(27.89)$ & $86.36(14.04)$ \\
\hline
\end{tabular}


Based on the positive responses to the RAQ and ST-segment analysis report of 12 lead ECG referring to either criteria 1 or 2 of $3^{\text {rd }}$ Universal definition of myocardial infarction, four categories of patients exhibiting the possibility of ischemic heart changes were identified. Out of the total 150 participants, both the positive responses to RAQ and ST-segment morphological changes revealed the potential ischemic heart changes among 34 (23\%) hypertensive patients (Table 4).

Besides, the majority of the study participants ( $n=103,69 \%)$ indicate the possible risk of IHDs based on the responses, either to RAQ or ST-segment analysis. The duration of hypertension, stage, and MAP of hypertensive individuals and their statistical associations with the presence of potential ischemic changes detected only through ST-segment morphological changes are represented in Table 5.

There were 66 individuals who responded positively to the first question of RAQ and all of them responded positively for at least one of the subsequent six questions in the RAQ. Importantly 36 hypertensive patients had provided positive responses to all seven questions in the RAQ, that denote possible ischemic heart changes. The chi-square values and the odds ratio that indicated the associations between different blood pressure parameters and the potential ischemic heart changes based on the responses only to the RAQ among 66 individuals are as in Table 6. The proportions of responses provided by the above 66 individuals for several questions in the RAQ are indicated in the Figure 2.

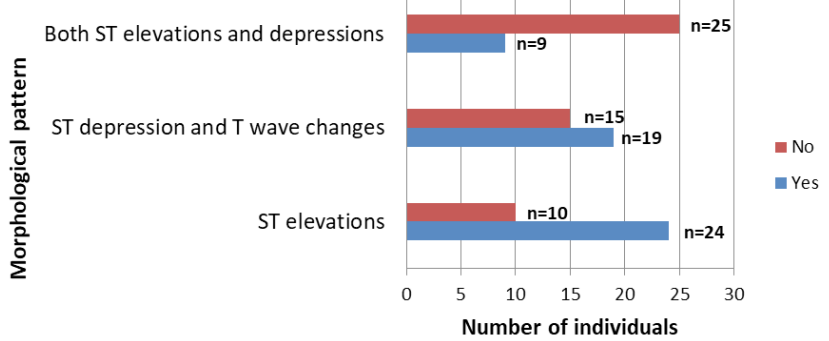

Figure 2:The prevalence of different ST-segment morphological patterns among the individuals who exhibited potential ischemic heart changes

Figure 1: The prevalence of selected NCDs in the study population

Table 4: The frequencies of four categories of patients who indicated potential IHDs changes based on RAQ and 12 lead ECG

\begin{tabular}{|c|c|c|c|c|c|c|}
\hline \multirow[b]{2}{*}{ Category } & \multirow{2}{*}{$\begin{array}{l}\text { Response to } \\
R A Q\end{array}$} & \multirow{2}{*}{$\begin{array}{l}\text { Ischemic changes in ST- } \\
\text { segment of } 12 \text { lead ECG }\end{array}$} & \multirow[b]{2}{*}{ Description } & \multicolumn{2}{|l|}{ Frequency } & \multirow[b]{2}{*}{ Total } \\
\hline & & & & Males (\%) & Female (\%) & \\
\hline Category 1 & + & + & Potential Risk of IHD & $17(50)$ & $17(50)$ & $34(23 \%)$ \\
\hline Category 2 & - & + & Risk group based on ECG changes only & $15(41)$ & $22(59)$ & $37(25 \%)$ \\
\hline Category 3 & + & - & $\begin{array}{l}\text { Risk group based on positive responses } \\
\text { to RAQ only }\end{array}$ & $11(34)$ & $21(66)$ & $32(21 \%)$ \\
\hline Category 4 & - & - & Non-risk group & $14(30)$ & $33(70)$ & $47(31 \%)$ \\
\hline Total Number & & & & 57 & 93 & $150(100 \%)$ \\
\hline
\end{tabular}

Table 5: The different blood pressure categories and their statistical associations with the presence of ischemic changes detected through STsegment deviations

\begin{tabular}{|c|c|c|c|c|c|}
\hline \multirow[t]{2}{*}{ Factor } & \multirow[t]{2}{*}{ Category } & \multicolumn{2}{|c|}{ ST-segment deviations } & \multirow{2}{*}{$\begin{array}{l}\text { Chi-square test } \\
\text { ( } p \text {-value) }\end{array}$} & \multirow{2}{*}{$\begin{array}{l}\text { Odds ratio } \\
\text { (with 95\% Cl) }\end{array}$} \\
\hline & & Positive & Negative & & \\
\hline \multirow[t]{2}{*}{ Duration of HTN } & 10 years or less & 50 & 58 & 0.683 & $0.862(0.422-1.759)$ \\
\hline & 11 years or more & 21 & 21 & & \\
\hline \multirow{2}{*}{$\begin{array}{l}\text { Belong to stage I or II } \\
\text { Hypertension }\end{array}$} & Yes & 52 & 69 & 0.029 & $0.397(0.17-0.924)$ \\
\hline & No & 19 & 10 & & \\
\hline \multirow[t]{2}{*}{ MAP (Hgmm) } & less than 100 & 32 & 34 & 0.802 & $1.086(0.569-2.071)$ \\
\hline & 100 or $100<$ & 39 & 45 & & \\
\hline
\end{tabular}

Table 6: The statistics indicating the associations between different blood pressure parameters

\begin{tabular}{|c|c|c|c|c|c|}
\hline \multirow[b]{2}{*}{ Factor } & \multirow[b]{2}{*}{ Category } & \multicolumn{2}{|c|}{ Responses to $R A Q$} & \multirow[b]{2}{*}{ Chi-test ( $p$-value) } & \multirow{2}{*}{$\begin{array}{l}\text { Odds ratio } \\
\text { (with 95\% Cl) }\end{array}$} \\
\hline & & Positive & Negative & & \\
\hline Duration of HTN & 10 or less than 10 & 49 & 59 & 0.588 & $1.221(0.593-2.517)$ \\
\hline (years) & 11 or more than 11 & 17 & 25 & & \\
\hline \multirow{2}{*}{$\begin{array}{l}\text { Belong to stage I or II } \\
\text { Hypertension }\end{array}$} & Yes & 52 & 69 & 0.606 & $0.807(0.358-1.819)$ \\
\hline & No & 14 & 15 & & \\
\hline \multirow[t]{2}{*}{ MAP (Hgmm) } & less than 100 & 29 & 37 & 0.989 & $1.00(0.520-1.906)$ \\
\hline & 100 or $100<$ & 37 & 47 & & \\
\hline
\end{tabular}


Table 7: The statistical association between different blood pressure categories and responses to both RAQ and ST analysis

\begin{tabular}{|c|c|c|c|c|c|}
\hline \multirow[b]{2}{*}{ Factor } & \multirow[b]{2}{*}{ Category } & \multicolumn{2}{|c|}{$\begin{array}{l}\text { Responses to both ST- } \\
\text { segment analysis and RAQ }\end{array}$} & \multirow{2}{*}{$\begin{array}{l}\text { Chi-square test } \\
\text { ( } p \text {-value) }\end{array}$} & \multirow{2}{*}{$\begin{array}{l}\text { Odds ratio } \\
\text { (with 95\% Cl) }\end{array}$} \\
\hline & & Positive & Negative & & \\
\hline \multirow[t]{2}{*}{ Duration of HTN (years) } & 10 or less than 10 & 25 & 83 & 0.821 & $1.104(0.466-2.615)$ \\
\hline & 11 or more than 11 & 9 & 33 & & \\
\hline \multirow{2}{*}{$\begin{array}{l}\text { Belong to stage I or II } \\
\text { Hypertension }\end{array}$} & Yes & 25 & 96 & 0.213 & $0.579(0.235-1.425)$ \\
\hline & No & 9 & 20 & & \\
\hline \multirow{2}{*}{$\begin{array}{l}\text { Mean arterial pressure } \\
(\mathrm{Hgmm})\end{array}$} & less than 100 & 17 & 49 & 0.423 & $1.367(0.635-2.943)$ \\
\hline & 100 or more than 100 & 17 & 67 & & \\
\hline
\end{tabular}

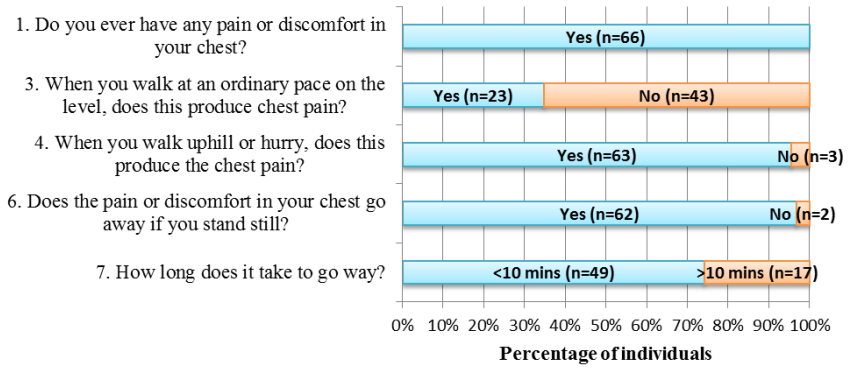

Figure 3: The proportions of responses provided for selected questions in the RAQ (the responses for $2^{\text {nd }}$ and $5^{\text {th }}$ question were not included in the figure as they inquired about the anatomical location of the chest pain and actions undertaken by the patients when they experience chest pain, respectively).

The chi-square values and the odds ratio that indicated the associations between different blood pressure parameters and the potential ischemic heart changes based on the responses only to the RAQ among 66 individuals are as follows in Table 6.

However, there were no statistically significant associations between different blood pressure parameters and possibly ischemic heart changes among 34 individuals who indicated positive responses to both RAQ and ST-segment morphological changes (Table 7).

\section{The prevalence of different morphological patterns of ST-segment}

The prevalence of different morphological patterns of ST-segment based on the $3^{\text {rd }}$ universal definition for $\mathrm{Ml}$ among 34 individuals is indicated who indicated positive responses to both RAQ and ST-segment morphological changes are as in the following Figure 3.

\section{Discussion}

The identification of potential ischemic heart changes among the hypertensive patients was achieved through the analysis of responses to RAQ and ST-segment measurements (in $\mathrm{mV}$ ) recordings. Hence, based on both positive responses to RAQ and ST-segment deviations, the proportion of individuals with potential ischemic heart changes among the hypertensive individuals was $23 \%$. A quarter (25\%) of Hypertensive individuals exhibited potential ischemic heart changes only in 12 lead ECG, but the responses to RAQ were negative. On the other hand, RAQ was positive for $21 \%$ of hypertensive individuals, though none of them exhibited any significant ST-segment changes in their 12 lead ECGs. Importantly according to the 1st question in RAQ, 66 individuals responded that saying they have ever experienced a chest pain and a considerable proportion of them responded positive for at least one of the subsequent question in the RAQ. Though there are no previous national research findings to compare the results of the current study, the study conducted by Rahman et al. in 2013 in Bangladesh has revealed that coronary heart diseases were positive among 160 (53\%) of their study participants only by means of RAQ. ${ }^{[16]}$ When considering the total number of hypertensive individuals in the current study, a considerable number $(\mathrm{n}=$ $103,69 \%$ ) denoted the potential risk of IHDs depending either on RAQ or ST analysis, respectively.

The frequencies of potential ischemic changes among the male and female in the current study were equal. However, a previous national study has found that cardiovascular diseases were more prevalent among males in Sri Lanka. ${ }^{[14]}$ Further analysis revealed that the majority of hypertensive individuals ( $n=67,44 \%$ ) suffer from hypercholesterolemia as well. Diabetes was noted among 10 (7\%) individuals, while 25 (17\%) had both diabetes and hypercholesterolemia, simultaneously. Though the statistical figure for diabetes (6\%) is nearly consistent as compared with the study of Mendis S and Ekanayake E M in 1994 in Central Sri Lanka, ${ }^{[13]}$ the prevalence of hypercholesterolemia among this hypertensive population was observed to be higher (12.6\%) than previous findings.

In the current hypertensive study group, the mean Systolic and Diastolic blood pressure were $146 \mathrm{Hgmm}(\mathrm{SD} \pm 23.28)$ and 85 $\mathrm{Hgmm}(\mathrm{SD} \pm 12.10)$, respectively. The average mean arterial pressure (MAP) was $104 \mathrm{Hgmm}$ (SD \pm 14.31). Referring to the categorization of hypertension by the American Heart Association guidelines in 2017 , in the current study population, the majority ( $n=121,80 \%)$ suffers from either stage I or II hypertension. Uncontrolled hypertension, itself has been substantiated as a risk factor for IHDs. ${ }^{[2]}$ Importantly the association between the ST segment deviations that mimic ischemic heart changes and the presence of stage I or II hypertension (Table 4) was statistically significant ( $p$ $=0.029, \mathrm{df}=1)$. Among $84(56 \%)$ of these hypertensive individuals, the MAP was more than $100 \mathrm{Hgmm}$, and the odds ratio was 1.086 $(95 \% \mathrm{Cl}, 0.569-2.071)$ suggesting that individuals with higher MAP are more prone to demonstrate potential IHDs changes than those having MAP below $100 \mathrm{Hgmm}$ in this study group. According to Sesso H D et al. in 2000, the relative risk for CVDs among the individuals with SBP $(\geq 130 \mathrm{HHgmm}), \mathrm{DBP}(\geq 81 \mathrm{HHgmm})$, and MAP $>97$ Hgmm were $2.16,2.23$ and 2.52 respectively. ${ }^{[17]}$

Among the individuals presenting with potential ischemic heart changes $(n=34)$, two ST-segment morphological patterns that indicated ischemic changes were identified. ST-segment elevations $>0.1 \mathrm{mV}$ in two contiguous ECG leads were the most prevalent $(n=24,71 \%$ ) morphological alterations followed by the ST depressions $\geq 0.05 \mathrm{mV}$ and/or T inversion $\geq 0.1 \mathrm{mV}$ among $19(56 \%)$ individuals. Further, 9 patients (26\%) indicated both of the above morphological alterations of ST segments in 12 lead ECG. A previous study has found that among 100 hypertensive patients studied, 
23 experienced 72 episodes ST-segment depression. During these ST depressions, systolic BP increased by $9+/-15 \mathrm{Hgmm}$, Diastolic BP $7+/-11 \mathrm{Hgmm}$. Thus it was concluded that BP elevations trigger the episodes of ST-segment depression, which denotes the ischemic changes in the heart (3). Further, in the study conducted by Uen S et al. in 2003, ST depressions > $1 \mathrm{~mm}$ was observed only among $26(41 \%)$ of the study population. Importantly, the study of Modak S et al. in 2016 on "ECG changes in chronic hypertensive patients" indicated that the ST depressions and T wave inversions commonly occur among the chronic hypertensive patients. ${ }^{[7]}$

Considering the local study findings, the prevalence of acute coronary syndrome among diabetic individuals in southern Sri Lanka as detected by validated Sinhala version of RAQ was $31 \%$ in 2013. The sensitivity and specificity of RAQ in predicting ischemic changes were $86.4 \%$ and $76 \%$, respectively, thus RAQ was accepted as a reliable tool for identifying the ischemic heart changes among the diabetic individuals in Sri Lanka. ${ }^{[14]}$

Unlike diabetes, uncontrolled hypertension directly affect the physiological function of the heart, therefore the use of RAQ in routine clinical assessment would reveal more indications related the ischemic heart changes among hypertensive individuals even in the absence of a 12 lead ECG on physician hand. Though there is a lack of previous similar studies in Sri Lanka to compare the current findings, the proportion of potential ischemic heart changes based on a positive response to RAQ and 12 lead ECG was higher in the present study, than that of the proportion of positive responses to RAQ (2\%) and ischemic changes in ECG (7.2\%) in the study conducted by Katulanda P et al. including 4484 healthy Sri Lankan adults, in 2010 (4).

\section{CONCLUSION}

According to the findings, the statistical association between the presence of ST-segment deviations as defined by the $3^{\text {rd }}$ Universal Definition of myocardial infarctions and the presence of stage I or II hypertension among the selected Sri Lankan adult population was statistically significant. Since nearly a quarter of the hypertensive individuals could be detected with potential ischemic heart changes based on positive responses to both RAQ and ST-segment analysis reports. it is suggestive that the RAQ and 12 lead ECG could play a valuable predictive role in identification of the symptoms of potential ischemic heart changes when carrying out the health assessment of Sri Lankan hypertensive adults. However, the lack of a control group and gold standard test findings such as Troponin test to emphasize the exact ischemic heart changes in each individual, has limited the calculation of sensitivity and specificity of using RAQ and ST segment morphological alterations in identthe ification of ischemic changes among the hypertensive individuals in the current study. Therefore, given the importance of preliminary findings of this study, a more comprehensive case control study need to be carried out to determine the definite role of RAQ and 12 lead ECG in detecting ischemic heart changes among Sri Lankan adult population.

\section{ACKnOWLedgment}

This study was financially supported by the university research grant (URG/2016/98/AHS) of the University of Peradeniya.

\section{References}

1. Annual Health Bulletin, 2014, Ministry of Health, Sri Lanka

2. Wilson PWF, D' Agostino RB, Levy D, et al. Prediction of Coronary Heart Disease using risk factor categories. Circulation, 1998, 97; 1837-1847

3. Asmar R, Benetos A, Pannier B, et al. Prevalence and circardian variations of ST- segment depression and its concomitant blood pressure changes in asymptomatic systemic hypertension, AMJ cardiol, 1996, 77(5): 384-90

4. Katulanda P, Liyanage IK, Caldera R et al, Prevalance of Ischaemic Heart Diseases and its risk factors in Sri Lanka, CMJ, 2010: 55 (supplement 1): pp 53 Available at http:// pgim.srilankahealthbiblio. org/handle/123456789/1308

5. Katulanda $P$, Ranasinghe $P$, jayawardene $R$, et al. The prevalence, predictors and associations of hypertension in Sri Lanka; a Cross-sectional population based national survey, ClinExpHypertens, 2014, 36(7) 1-8

6. Birnbaum Y, Wison JM, Fiol $\mathrm{M}$ et al, ECG Diagnosis and Classification of Acute Coronary Syndromes, Ann Noninvasive Electrocardiol, 2014: 19(1); 4-14

7. Modak, S, Mehta, P, Patnaik J, Study on ECG changes in Chronic Hypertensive Patterns in a Medical College Hospital in Odisha, Journal of Medical Science and Clinical Research, 2016: 4(5); Available at http:// dx.doi.org/10.18535/jmscr/v4i5.14

8. Stramba-Badiale M, Bonazzi, $\mathrm{O}$, Casadei G, et al. prevalence of episodes of ST segment depression among mild to moderate hypertensive patients in northern Italy: the cardio screening study, J. Hypertens, 1998;16(5): 681-688

9. Uen S, Baulmann J, Dusing R, et al. ST segment depression in hypertensive patients in linked to elevations in blood pressure, pulse pressure and double Product by $24 \mathrm{~h}$ Cardiotens monitoring, $J$ Hypertens, 2003;21(5): 977-983.

10. Jahrsdoerfr M, Giuliano K, Stephens D, Clinical usefulness of the EASI 12 lead continuous Electrocardiographic monitoring system, Critical Care Nurse, 2005: 25 (5): 28-37Available at http://ccn.aacnjournals.org/

11. Rose G, The diagnosis of ischemic heart pain and intermittent claudication in field surveys, Bull World Health Organ, 1962, 27; 645-658

12. Fischbacher CM, Bhopal R, Unwin N, et al. The performance of the Rose Angina Questionnaire in South Asian and European origin populations: A comparative study in Newcastle, UK, International Journal of Epidemiology, 2001, 30; 1009-1016

13. Liyanage, P, Sathananthan, P., Prevalence of myocardial ischaemia among diabetics determined by validated Sinhala version of the WHO Rose angina questionnaire, Galle Medical Journal, 2013,18(1);12-15 Available at http://doi.org/10.4038/gmj.v18i1.5522

14. Nanayakkara SDT, Validation of the rose angina questionnaire and the resting electrocardiogram against the exercise electrocardiogram for screening of coronary heart diseases, University of Peradeniya UP (MED), 2002:xvii, 234 Available at http://hellis.srilankahealthrepository. org/handle/123456789/7944

15. Mendis S, Ekanayake EM, Prevalence of coronary heart disease and cardiovascular risk factors in middle aged males in a defined population in Central Sri Lanka, Int J Cardiol, 1994:46 (2): 135-142

16. Rahman MA, Spurrier, N, Mahmood MA, etal. Rose Angina Questionnaire, Validation with cardiologist diagnoses to detect coronary heart disease in Bangladesh, Indian Heart Journal, 2013; 65(1); 30-39

17. Sesso HD, Stampfer MJ, Rosner B, et al. Systolic and Diastolic Blood Pressure, Pulse Pressure and Mean Arterial Pressure as predictors of cardiovascular disease risk in men, hypertension, 2000, 36; 801-807

18. Mansournia MA, Holakouie-Naieni K, Fahimfar N, Almasi-Hashiani A, Cheraghi Z, Ayubi E, Hadaegh F, Eskandari F, Azizi F, Khalili D. Risk of Coronary Heart Events Based on Rose Angina Questionnaire and ECG Besides Diabetes and Other Metabolic Risk Factors: Results of a 10-Year Follow-up in Tehran Lipid and Glucose Study. International journal of endocrinology and metabolism. 2017 Apr;15(2). 